\title{
Effect of Vitamin D Supplementation on Skeletal Muscle Volume and Strength in Patients with Decompensated Liver Cirrhosis Undergoing Branched Chain Amino Acids Supplementation: A Prospective, Randomized, Controlled Pilot Trial
}

\author{
Tomomi Okubo ${ }^{1}$, Masanori Atsukawa ${ }^{1,2, * \mathbb{D}}$, Akihito Tsubota ${ }^{3} \mathbb{D}$, Hiroki Ono ${ }^{2}$, Tadamichi Kawano ${ }^{2}$, \\ Yuji Yoshida ${ }^{1}$, Taeang Arai ${ }^{2}$, Korenobu Hayama ${ }^{1}$, Norio Itokawa ${ }^{2}$, Chisa Kondo ${ }^{2}$, Keiko Kaneko ${ }^{2}$ \\ and Katsuhiko Iwakiri ${ }^{2}$
}

check for

updates

Citation: Okubo, T.; Atsukawa, M.; Tsubota, A.; Ono, H.; Kawano, T.; Yoshida, Y.; Arai, T.; Hayama, K.; Itokawa, N.; Kondo, C.; et al. Effect of Vitamin D Supplementation on Skeletal Muscle Volume and Strength in Patients with Decompensated Liver Cirrhosis Undergoing Branched Chain Amino Acids Supplementation: A Prospective, Randomized, Controlled Pilot Trial. Nutrients 2021, 13, 1874. https://doi.org/10.3390/ nu13061874

Academic Editors: Aldo J. Montano-Loza and Maryam Ebadi

Received: 29 April 2021

Accepted: 27 May 2021

Published: 30 May 2021

Publisher's Note: MDPI stays neutral with regard to jurisdictional claims in published maps and institutional affiliations.

Copyright: (c) 2021 by the authors. Licensee MDPI, Basel, Switzerland. This article is an open access article distributed under the terms and conditions of the Creative Commons Attribution (CC BY) license (https:// creativecommons.org/licenses/by/ $4.0 /)$.
1 Department of Internal Medicine, Division of Gastroenterology, Nippon Medical School Chiba Hokusoh Hospital, Inzai 270-1694, Japan; ma6-0154@nms.ac.jp (T.O.); yuji-y@nms.ac.jp (Y.Y.); leaf0710@nms.ac.jp (K.H.)

2 Department of Internal Medicine, Division of Gastroenterology and Hepatology, Nippon Medical School, Tokyo 113-8603, Japan; h-ono0@nms.ac.jp (H.O.); k-tadamichi@nms.ac.jp (T.K.); taeangpark@yahoo.co.jp (T.A.); itokawa@nms.ac.jp (N.I.); s8042@nms.ac.jp (C.K.); catcatkeiko1009@nms.ac.jp (K.K.); k-iwa@nms.ac.jp (K.I.)

3 Core Research Facilities, The Jikei University School of Medicine, Tokyo 105-0003, Japan; atsubo@jikei.ac.jp

* Correspondence: momogachi@yahoo.co.jp; Tel.: +81-3-3822-2131; Fax: +81-3-5802-1947

Abstract: Background: Sarcopenia worsens patient prognoses in chronic liver disease. This study aimed to elucidate the effects of vitamin D supplementation on skeletal muscle volume and strength in patients with decompensated cirrhosis. Methods: Thirty-three patients were entered into the study based on the criteria and then randomly assigned to two groups: Group A ( $n=17)$, the control group, and Group B $(n=16)$, those who received oral native vitamin D3 at a dose of 2000 IU once a day for 12 months. Results: SMI values in Group B were significantly increased at 12 months $\left(7.64 \times 10^{-3}\right)$. The extent of changes in the SMI and grip strength in Group B were significantly greater than that in Group A at 12 months $\left(p=2.57 \times 10^{-3}\right.$ and $\left.9.07 \times 10^{-3}\right)$. The median change rates in the SMI were $+5.8 \%$ and the prevalence of sarcopenia was significantly decreased from $80.0 \%(12 / 15)$ to $33.3 \%$ $\left(5 / 15 ; p=2.53 \times 10^{-2}\right)$ in Group B. Conclusions: Vitamin D supplementation might be an effective and safe treatment option for patients with decompensated cirrhosis to increase or restore the skeletal muscle volume and strength or prevent the muscle volume and strength losses.

Keywords: vitamin D; decompensated liver cirrhosis; sarcopenia; skeletal muscle mass index

\section{Introduction}

Sarcopenia is characterized by generalized loss of skeletal muscle volume and strength. It is divided into two categories: "primary" sarcopenia, due to aging but not due to other causes, and "secondary" sarcopenia, due to underlying diseases, such as chronic liver, kidney and inflammatory diseases, as well as malignant tumors [1,2]. Sarcopenia, especially primary sarcopenia, causes a decline in physical fitness and health-related quality of life among community-dwelling elderly individuals [3]. Secondary sarcopenia worsens patient prognoses in various diseases, such as chronic obstructive pulmonary disease, malignant tumors and liver cirrhosis [4-7]. For patients with cirrhosis, early diagnosis and appropriate treatment for sarcopenia are important [8]. In Japan, patients with chronic liver disease are diagnosed with sarcopenia based on the criteria proposed by the Japan Society of Hepatology (JSH) [9]. The reported strategies for treating sarcopenia related to chronic 
liver disease include exercise regimens and supplementation with branched-chain amino acid (BCAA) [4,8,10-12]; however, a definitive treatment has not yet been established. For instance, exercise may induce some adverse effects, such as increased ammonia production in the muscle and elevated portal pressures $[13,14]$. The prevalence of sarcopenia is high in patients with advanced fibrosis $[3,9,15]$; thus, an effective and safe treatment for sarcopenia in patients with cirrhosis is urgently needed.

Vitamin D is a group of fat-soluble secosteroids and plays a crucial role in cell proliferation and differentiation, bone calcification, bone growth and remodeling, nerve and muscle functions, immune regulation and inflammation improvement [16]. The actions of vitamin $\mathrm{D}$ are mediated via the vitamin $\mathrm{D}$ receptor (VDR), which is a member of the nuclear receptor family of transcription factors and is expressed in systemic tissues, including the skeletal muscle [17]. We previously reported that patients with chronic liver diseases have low vitamin D levels $[18,19]$, affecting the response to interferon therapy in patients with chronic hepatitis C [20]. Vitamin D is also involved in the development of arteriosclerosis in patients with non-alcoholic fatty liver disease [21]. Furthermore, low vitamin D is an independent factor for sarcopenia in patients with chronic liver disease $[15,22]$. The skeletal muscle cells strongly express the VDR [23,24], which is necessary to maintain muscle volume [25]. In the elderly, vitamin D deficiency is associated with reduced muscle volume, muscular strength and motor function, which results in an increased risk of falling [26-30]. Furthermore, vitamin D deficiency is an independent factor for sarcopenia in the elderly [31]. Although vitamin D supplementation improves the appendicular muscle volume and reduces the frequency of falls in elderly individuals [32,33], to the best of our knowledge, no study as of yet has investigated the influence of vitamin $\mathrm{D}$ supplementation on the skeletal muscle volume and strength in patients with chronic liver disease. Specifically, vitamin D deficiency and sarcopenia develop more frequently in patients with cirrhosis $[9,15,34]$. Thus, the improvement of these unfavorable conditions is essential for such patients.

In the present study, we aimed to elucidate the effects of vitamin D supplementation on skeletal muscle volume and strength in patients with decompensated cirrhosis, who are most frequently complicated by vitamin D deficiency and reduced skeletal muscle volume and strength.

\section{Materials and Methods}

\subsection{Patients}

Patients with decompensated cirrhosis who had been receiving oral BCAA preparations at Nippon Medical School Chiba Hokusoh Hospital (Chiba, Japan) between March 2017 and March 2019 were enrolled in the study. They were randomly assigned to two groups: Group A, the control group with no vitamin D supplementation, and Group B, those who received oral vitamin D supplements. This study was an open-label study. The leading inclusion criteria were as follows: (1) presence of decompensated cirrhosis; (2) age $\geq 20$ years; (3) oral BCAA treatment that had already been initiated 6 months before the date of entry and would be continued during the study period. We routinely administered BCAA preparations to patients with decompensated cirrhosis to improve hypoalbuminemia $(\leq 3.5 \mathrm{~g} / \mathrm{dL})$. Thus, almost all of the patients with decompensated cirrhosis received BCAA preparations at our hospital. Therefore, receiving BCAA treatment for a certain period was added to the inclusion criteria to eliminate or reduce the influence of BCAA. The exclusion criteria were as follows: (1) serum 25-hydroxyvitamin D [25(OH)D] level $\geq 30 \mathrm{ng} / \mathrm{mL}$; (2) uncontrolled ascites; (3) uncontrolled malignant tumors including hepatocellular carcinoma (HCC); (4) jaundice or hyperbilirubinemia ( $\geq 3 \mathrm{mg} / \mathrm{dL}$ ); (5) grade 3 or 4 hepatic encephalopathy; (6) chronic renal failure; (7) hypercalcemia; (8) hyperparathyroidism; (9) pacemaker use; (10) vitamin D supplementation within 6 months before the date of entry. 


\subsection{Study Protocol}

Of the 102 adult patients with cirrhosis, 57 had decompensated cirrhosis to which BCAA preparations (LIVACT ${ }^{\circledR}$; EA pharma, Tokyo, Japan) were administered. Based on the criteria described above, 24 patients were excluded and 33 patients were included in this study. The 33 patients were randomly assigned to Group A $(n=17)$ or Group B $(n=16)$ after enrollment, using a random number table (Figure 1). The sample size was calculated to be $n=18.4$ with the problem probability set to 0.15 and the confidence level set to $95 \%$, which was used as a reference for the sample size. Immediately after the allocation, the patients in Group B received oral native vitamin D3 (Now ${ }^{\circledR} 244$ Knollwood Dr, Bloomingdale, IL 60108, USA) at a dose of $2000 \mathrm{IU}$ once a day for 12 months. We administered oral native vitamin $\mathrm{D} 3$ at a dose of D in simeplever and pegylated interferon/ribavirin combination therapy in hepatitis $C$ patients and set the same amount this time because it was safe and effective [20]. The patients in both groups underwent physical and laboratory examinations, including measurement of serum 25(OH)D levels, skeletal muscle mass index (SMI) and grip strength, every 3 months during the study period. Patients' adherence to vitamin D supplementation was also calculated. Day 0 was set as the time of entry in Group A and the initiation of vitamin D supplementation in Group B. Primary outcomes were changes in SMI and grip strength after 12 months and secondary outcomes were frequency of sarcopenia and safety.

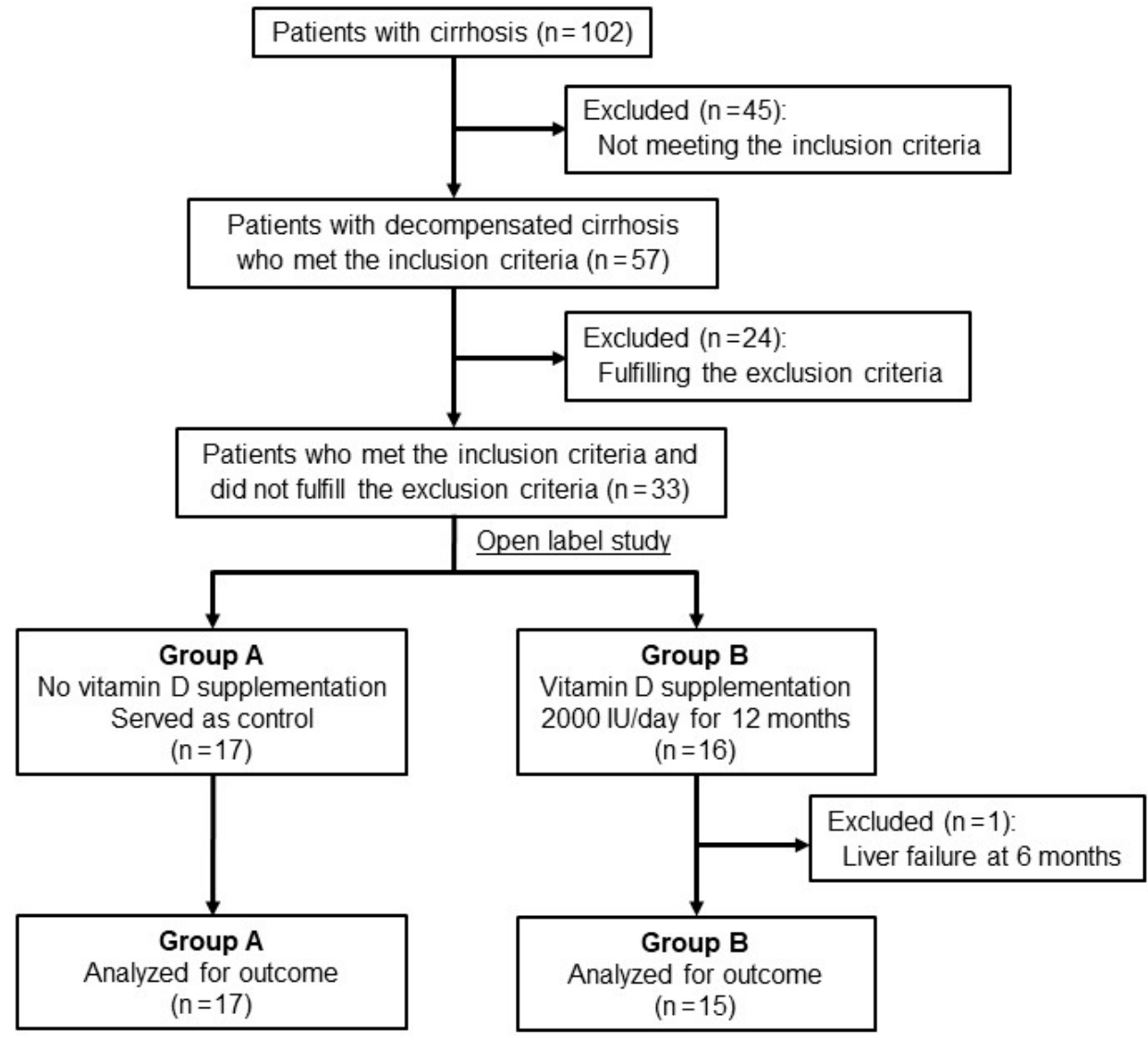

Figure 1. Flow diagram of patients included in the present study.

\subsection{Laboratory Methods}

Hematological, biochemical and clotting tests (Table 1), which were routinely measured using conventional methods, were conducted on day 0. Serum $25(\mathrm{OH}) \mathrm{D}$ levels, a representative marker of vitamin $\mathrm{D}$ status, were measured using a double-antibody radioimmunoassay kit (SRL, Tokyo, Japan). Vitamin D deficiency was defined as a serum 25(OH)D level of $\leq 20 \mathrm{ng} / \mathrm{mL}$ [35]. 
Table 1. Baseline patient characteristics of control group (Group A) and vitamin D supplementation group (Group B).

\begin{tabular}{|c|c|c|c|}
\hline Factors & Group A $(n=17)$ & Group B $(n=15)$ & $p$ Value \\
\hline Age (years) & $70(55-88)$ & $73(64-86)$ & 0.226 \\
\hline Gender (male/female) & $7 / 10$ & $6 / 9$ & 1.000 \\
\hline $\operatorname{BMI}\left(\mathrm{kg} / \mathrm{m}^{2}\right)$ & $24.0(15.0-31.6)$ & $22.0(17.6-27.3)$ & 0.109 \\
\hline $\begin{array}{l}\text { Etiology of chronic hepatitis } \\
\mathrm{HCV} / \mathrm{HBV} / \text { alcohol/NAFLD/PBC/AIH }\end{array}$ & $7 / 1 / 6 / 2 / 1 / 0$ & $8 / 0 / 2 / 3 / 1 / 1$ & - \\
\hline History of HCC treatment (yes/no) & $5 / 12$ & $4 / 11$ & 1.000 \\
\hline Leukocytes $\left(/ \mathrm{mm}^{3}\right)$ & $4170(2250-5980)$ & $4700(2980-5980)$ & 0.428 \\
\hline Hemoglobin (g/dL) & $13.2(10.0-15.6)$ & $12.2(7.9-14.6)$ & 0.184 \\
\hline Platelets $\left(\times 10^{3} / \mathrm{mm}^{3}\right)$ & $86(39-169)$ & $156(55-213)$ & 0.079 \\
\hline AST (U/L) & $42(23-143)$ & $25(16-99)$ & 0.104 \\
\hline ALT (U/L) & $18(9-43)$ & $17(7-63)$ & 0.241 \\
\hline$\gamma$-GTP $(\mathrm{U} / \mathrm{L})$ & $61(18-374)$ & $23(11-72)$ & $6.10 \times 10^{-4}$ \\
\hline Calcium (mg/dL) & $8.9(7.9-10.1)$ & $8.9(7.9-10.0)$ & 0.138 \\
\hline Inorganic phosphorus (mg/dL) & $3.2(2.4-3.6)$ & $3.3(2.0-3.8)$ & 0.816 \\
\hline Total bilirubin (mg/dL) & $1.3(0.5-2.4)$ & $0.8(0.5-2.2)$ & $2.06 \times 10^{-2}$ \\
\hline Serum albumin (g/dL) & $3.3(2.3-3.8)$ & $3.0(2.4-3.8)$ & 0.117 \\
\hline Total cholesterol (mg/dL) & $153(112-206)$ & $181(99-222)$ & 0.095 \\
\hline Serum creatinine $(\mathrm{mg} / \mathrm{dL})$ & $0.67(0.42-2.91)$ & $0.75(0.52-1.41)$ & 0.590 \\
\hline Prothrombin time (\%) & $79.1(47.9-98.4)$ & $68.1(46.9-100.2)$ & 0.443 \\
\hline Alpha-fetoprotein (ng/mL) & $7.20(1.02-124.90)$ & $2.57(1.39-27.24)$ & 0.279 \\
\hline $\mathrm{WFA}^{+}-\mathrm{M} 2 \mathrm{BP}$ (C.O.I) & $3.96(1.53-12.35)$ & $2.88(1.07-13.01)$ & 0.702 \\
\hline Serum 25(OH)D3 (ng/mL) & $15.0(5.4-25.5)$ & $13.2(6.1-19.2)$ & 0.606 \\
\hline BCAA administration period (months) & $45(4-80)$ & $23(9-46)$ & 0.089 \\
\hline Grip strength $(\mathrm{kg})$ & $18(10-30)$ & $16(7-25)$ & 0.157 \\
\hline $\mathrm{SMI}\left(\mathrm{kg} / \mathrm{m}^{2}\right)$ & $6.8(5.1-8.3)$ & $5.5(4.9-7.6)$ & $1.10 \times 10^{-2}$ \\
\hline FFM (kg) & $43.3(34.4-56.0)$ & $34.4(31.0-56.4)$ & 0.212 \\
\hline PBF (\%) & $31.2(19.3-46.5)$ & $33.9(13.1-46.3)$ & 0.935 \\
\hline Sarcopenia (yes/no) & $8 / 9$ & $12 / 3$ & 0.120 \\
\hline
\end{tabular}

Categorical variables are given as numbers. Continuous variables are given as medians and ranges in parentheses. BMI, body mass index; HCV, hepatitis C virus; HBV, hepatitis B virus; NAFLD, nonalcoholic fatty liver disease; PBC, primary biliary cholangitis; $\mathrm{AIH}$, autoimmune hepatitis; HCC, hepatocellular carcinoma; AST, aspartate aminotransferase; ALT, alanine aminotransferase; $\gamma$-GTP, gamma-glutamyltransferase; $\mathrm{WFA}^{+}-\mathrm{M} 2 \mathrm{BP}$, Wisteria floribunda agglutinin positive Mac-2-binding protein; COI, cut-off index; 25(OH)D3, 25-hydroxyvitamin D3; BCAA, branched-chain amino acid; SMI, skeletal muscle mass index; FFM, fat free mass; PBF, percentage of body fat.

\subsection{Diagnosis of Sarcopenia}

Grip strength was measured using the Smedley spring-type grip force meter. Two measurements were obtained from each hand and the average of the higher right- and leftsided values was recorded as the grip strength value. Bioelectrical impedance analysis was conducted using InBody 270 (Biospace, Seoul, Korea) to estimate the appendicular skeletal muscle volume, which was calculated as the sum of the bilateral upper and lower extremity lean muscle volume. The SMI, which is a validated indicator of sarcopenia, was calculated as follows: SMI $\left(\mathrm{kg} / \mathrm{m}^{2}\right)=$ appendicular skeletal muscle volume $(\mathrm{kg}) /[\text { height }(\mathrm{m})]^{2}$. The diagnosis of sarcopenia was based on the criteria proposed by the JSH [3]. According to the JSH criteria, sarcopenia is defined as the presence of decreased handgrip strength $(<26 \mathrm{~kg}$ 
for men and $<18 \mathrm{~kg}$ for women) and decreased muscle mass (SMI $<7.0 \mathrm{~kg} / \mathrm{m}^{2}$ for men and $<5.7 \mathrm{~kg} / \mathrm{m}^{2}$ for women).

\subsection{Ethical Statement}

The present study followed the ethical guidelines established in accordance with the 2013 Declaration of Helsinki and was approved by the Institutional Review Board of Nippon Medical School Foundation (approval number: nms-2019-0102-01). All patients provided written informed consent.

\subsection{Statistical Analyses}

The Fisher exact test was used to compare frequencies in categorical data between two groups. Continuous variables with skewed distribution were compared between two groups using the Mann-Whitney test. The Wilcoxon-rank sum test was used to compare two matched samples on the same case. The level of statistical significance was set at $p<0.05$. All statistical analyses were performed using SPSS version 17.0 software (IBM Japan, Tokyo, Japan).

\section{Results}

\subsection{Patient Characteristics}

One patient in Group B was excluded from the present analysis due to death from liver failure at 6 months. Table 1 presents the baseline characteristics of Group A ( $n=17)$ and Group B $(n=15)$. Gamma-glutamyltransferase, total bilirubin and SMI significantly differed between the two groups. No other significant differences were observed.

\subsection{Changes in Serum $25(\mathrm{OH}) \mathrm{D}$, Albumin and Prothrombin Time}

Serum 25(OH)D levels did not significantly change between day 0 and 12 months in Group A (median (range), 15.0 (5.4-25.5) ng/mL vs. $14.3(4.7-20.6) \mathrm{ng} / \mathrm{mL} ; p=0.193)$. Contrarily, serum 25(OH)D levels were significantly increased in Group B (13.2 (6.1-19.2) $\mathrm{ng} / \mathrm{mL}$ vs. $34.4(18.5-43.9) \mathrm{ng} / \mathrm{mL} ; p=9.82 \times 10^{-4}$ Figure 2$)$. Serum $25(\mathrm{OH}) \mathrm{D}$ levels were $<20 \mathrm{ng} / \mathrm{mL}$ at day 0, which corresponds to the definition of vitamin D deficiency [34], and were increased at 12 months in all the patients in Group B. Serum 25(OH)D levels were $\geq 20 \mathrm{ng} / \mathrm{mL}$ in all but one patient in Group B at 12 months. No significant changes in serum albumin and prothrombin time were observed in either of the groups.

\subsection{Changes in the SMI, Grip Strength, BMI, FFM and PBF}

In Group $\mathrm{A}$, the SMI and grip strength did not significantly change between day 0 and 12 months ( $p=0.158$ and 0.906 , respectively). In Group B, the SMI were significantly increased from day 0 to 12 months $\left(p=7.64 \times 10^{-3}\right.$; Figure 3$)$. The maximum $/$ minimum values and the first/third quartiles (but not median) of grip strength were increased from day 0 to 12 months, although the difference was not statistically significant $(p=0.463)$. In Group A, the body mass index (BMI) (median (range), $24.0(15.0-31.6) \mathrm{kg} / \mathrm{m}^{2}$ vs. 25.3 $\left.(14.9-32.8) \mathrm{kg} / \mathrm{m}^{2} ; p=0.507\right)$ ), fat free mass (FFM) (median (range), 43.3 (34.4-56.0) kg vs. $42.6(32.3-57.1) \mathrm{kg} ; p=0.779)$ ) and percentage of body fat (PBF) (median (range), 31.2 $(19.3-46.5) \%$ vs. $31.5(17.5-46.9) \% ; p=0.285)$ ) did not change significantly between day 0 and 12 months. Similarly in Group B, the BMI (median (range), $22.0(17.6-27.3) \mathrm{kg} / \mathrm{m}^{2}$ vs. $\left.22.3(17.3-27.1) \mathrm{kg} / \mathrm{m}^{2} ; p=0.721\right)$ ), FFM (median (range), $34.4(31.0-56.4) \mathrm{kg}$ vs. 35.5 (29.3-56.3) kg; $p=0.553)$ ) and PBF (median (range), $33.9(13.1-46.3) \%$ vs. $33.8(12.7-46.0) \%$; $p=0.678)$ ) did not change significantly between day 0 and 12 months. 

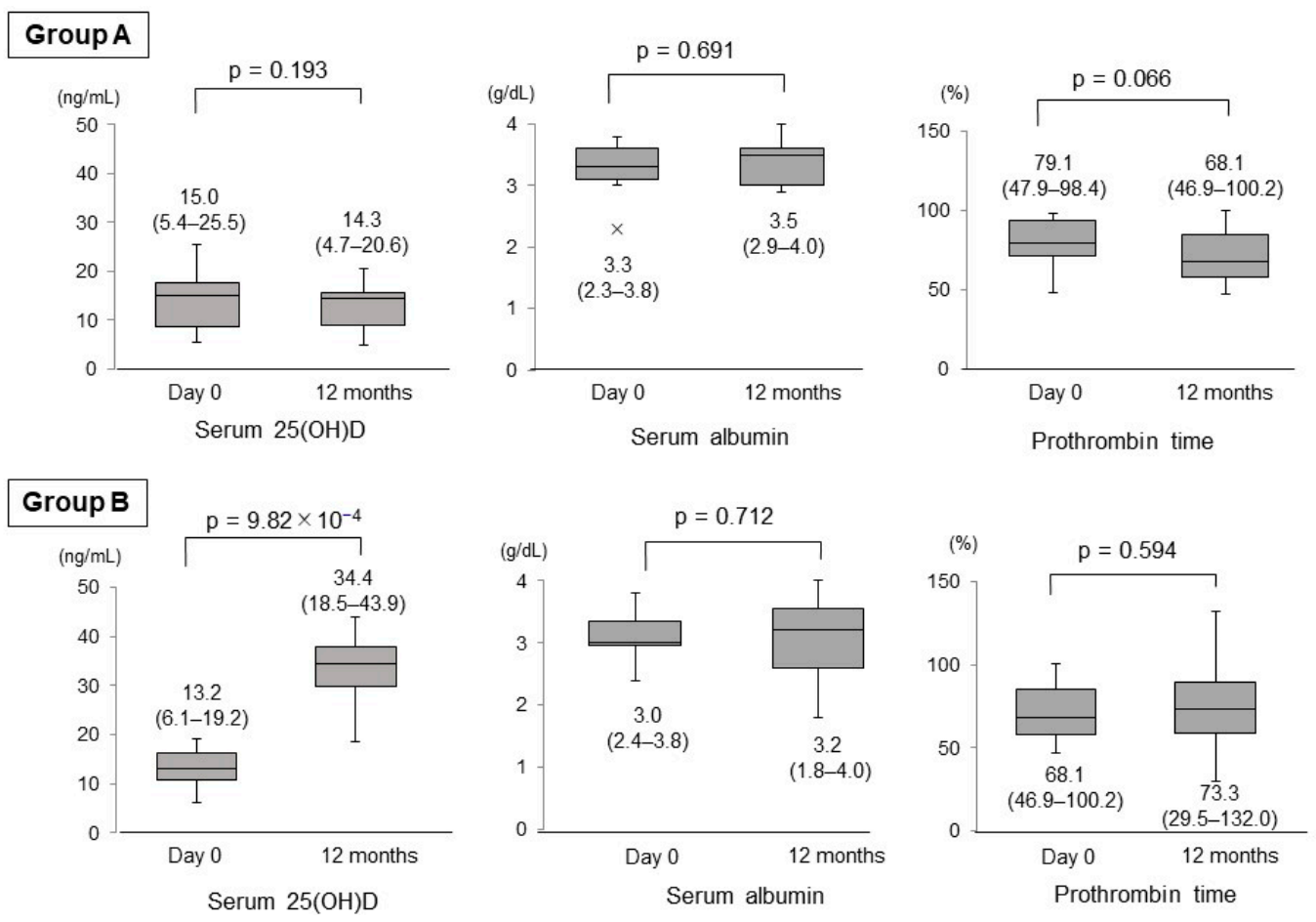

Figure 2. Changes in the levels of serum $25(\mathrm{OH}) \mathrm{D}$, serum albumin and prothrombin time between day 0 and 12 months in the untreated (Group A) and vitamin D-treated (Group B) patients.

\section{Group A}

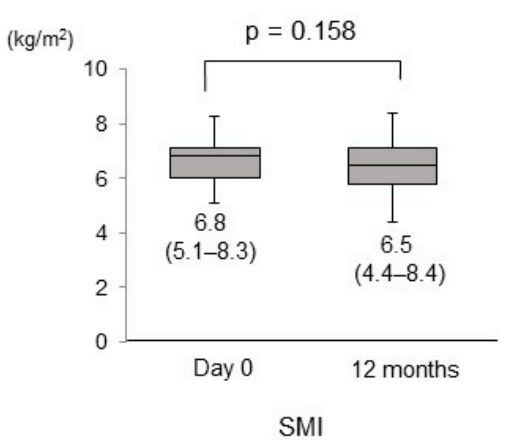

\section{Group B}

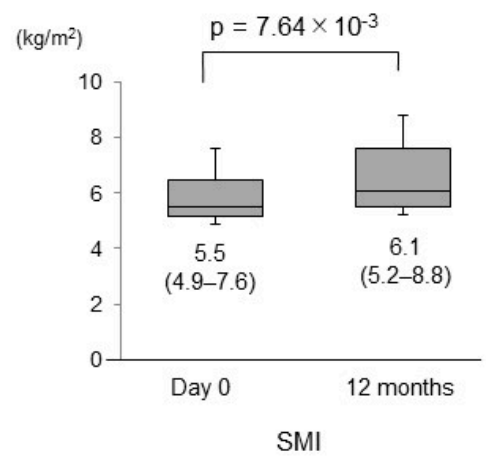

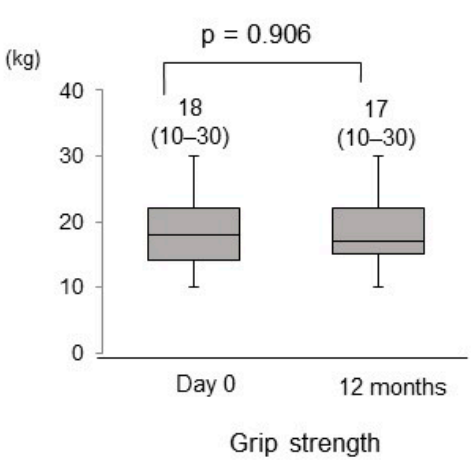

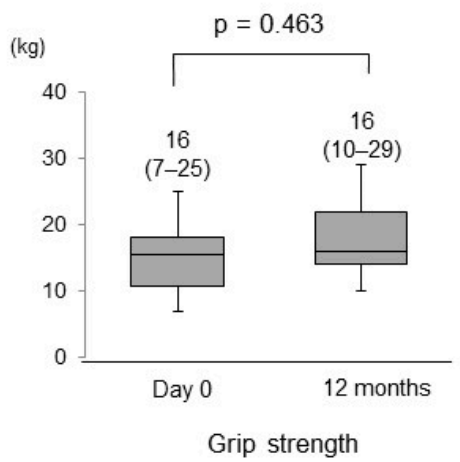

Figure 3. Changes in the skeletal muscle mass index and grip strength between day 0 and 12 months in the untreated (Group A) and vitamin D-treated (Group B) patients. 


\subsection{Comparison of the Changes in the SMI and Grip Strength between Group A and Group B}

The extent of changes in the SMI from day 0 to 12 months in Group B was significantly greater than that in Group A $\left(p=2.57 \times 10^{-3}\right.$; Figure 4). The extent of changes in grip strength from day 0 to 12 months in Group B was significantly higher than that in Group A $\left(p=9.07 \times 10^{-3}\right.$; Figure 4$)$.
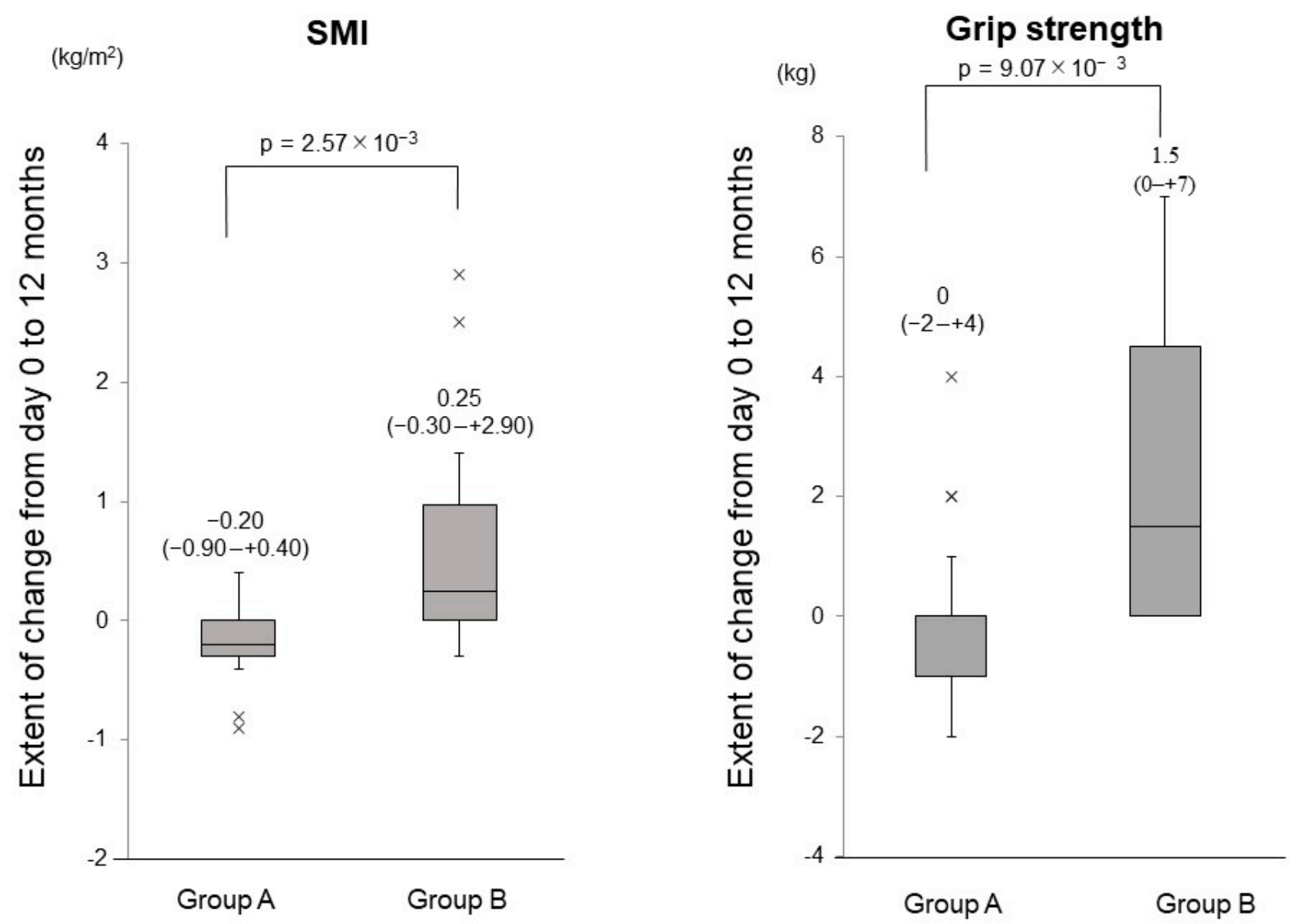

Figure 4. The extent of changes in the skeletal muscle mass index (SMI) and grip strength between day 0 and 12 months in the untreated (Group A) and vitamin D-treated (Group B) patients.

\subsection{Time Course of the Change Rates in the SMI and Grip Strength}

The change rates in the SMI from day 0 were $-1.8 \%$ at 6 months and $-3.3 \%$ at 12 months in Group A. Contrarily, the median change rates in the SMI were $+5.4 \%$ at 6 months and $+5.8 \%$ at 12 months in Group B. Significant differences in the change rates between the two groups were observed at 6 months and 12 months $\left(p=2.59 \times 10^{-3}\right.$ and $8.57 \times 10^{-4}$, respectively; Figure 5). Meanwhile, the median change rates in grip strength from day 0 were $0 \%$ at 6 and 12 months in Group A and $0 \%$ at 6 months and $+8.0 \%$ at 12 months in Group B. A significant difference in the change rates between the two groups was observed at 12 months $\left(p=1.40 \times 10^{-2}\right.$; Figure 5). 
(\%)

15

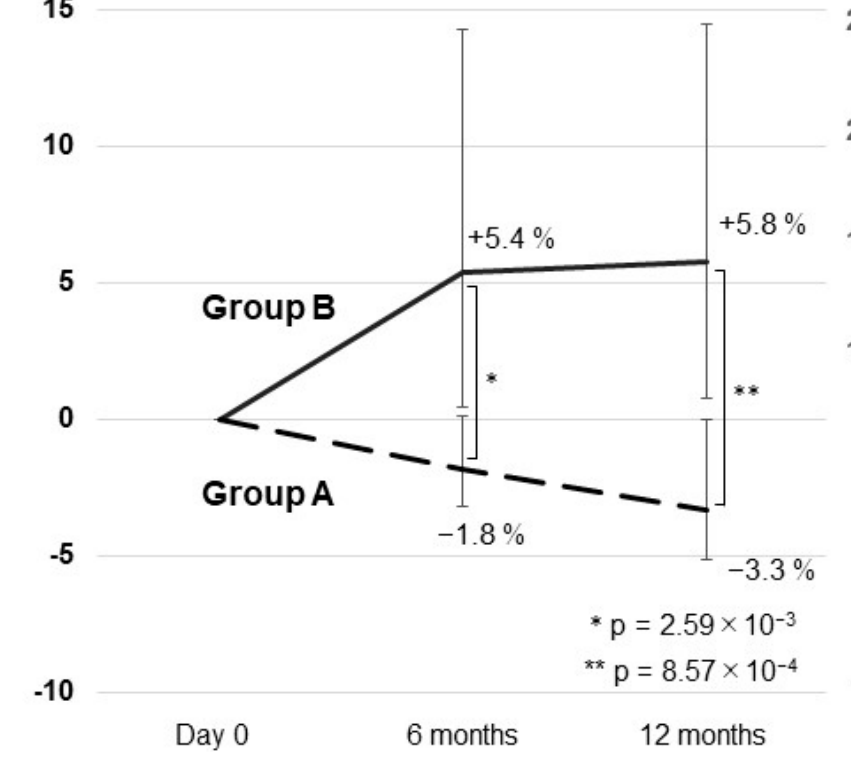

(\%)

25

20

15
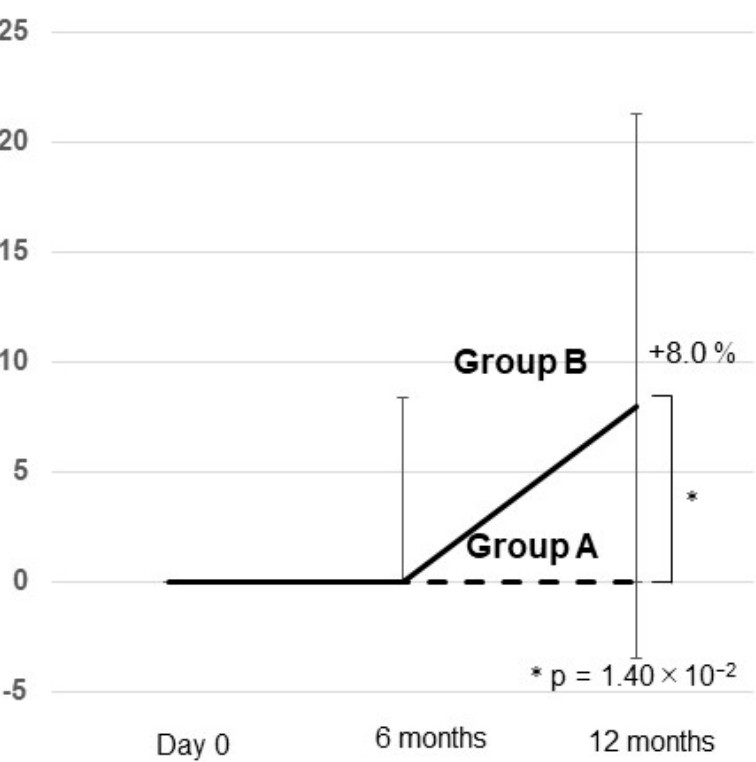

Day 0

\section{Grip strength}

Figure 5. Time-course of the change rates in the skeletal muscle mass index (SMI) and grip strength in the untreated (Group A) and vitamin D-treated (Group B) patients. The error bar represents the quartile.

These results demonstrated that vitamin D supplementation increased the skeletal muscle volume or restored the muscle volume and increased the muscle strength in patients with decompensated cirrhosis receiving BCAA preparations.

\subsection{Prevalence of Sarcopenia in Group A and Group B}

Sarcopenia was diagnosed in 8 patients in Group A $(8 / 17 ; 47.1 \%)$ and in 12 patients in Group B $(12 / 15 ; 80.0 \%)$. In Group A, 3 patients were newly diagnosed with sarcopenia at 12 months, while the 8 patients with sarcopenia at day 0 remained sarcopenic at 12 months. Thus, the prevalence of sarcopenia was increased to $64.7 \%(11 / 17)$ at 12 months, although the difference was not significant $(p=0.491)$. Contrarily, 7 out of 12 patients diagnosed with sarcopenia at day 0 no longer met the sarcopenia diagnostic criteria at 12 months in Group B. Moreover, no patient was newly diagnosed with sarcopenia at 12 months in Group B. Thus, the prevalence of sarcopenia was significantly decreased from $80.0 \%$ $(12 / 15)$ to $33.3 \%\left(5 / 15 ; p=2.53 \times 10^{-2}\right)$ at 12 months (Figure 6). These results suggest that vitamin D supplementation may be useful for treating sarcopenia in patients with decompensated cirrhosis receiving BCAA preparations.

\subsection{Adverse Events and Oral Compliance}

No significant changes in the levels of calcium, inorganic phosphorus and creatinine were observed between day 0 and 12 months in Group A or Group B (Table 2). The patients demonstrated no symptoms due to hypercalcemia, such as anorexia, diarrhea, constipation, nausea, vomiting, sleepiness, headache, muscle pain, thirstiness, weakness and renal calculi. Patients' adherence to vitamin D supplementation was excellent (adherence rates: $95-100 \%$ ). One patient was excluded from the current analysis due to death from liver failure at 6 months, but this case eventually died of liver failure due to hepatorenal syndrome type 1 caused by cholecystitis. Therefore, it is considered that it is not related to Vitamin D administration. 
(\%)

100

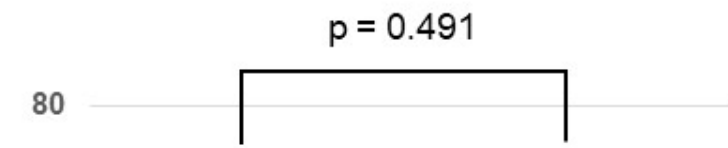

$64.7 \%$

60
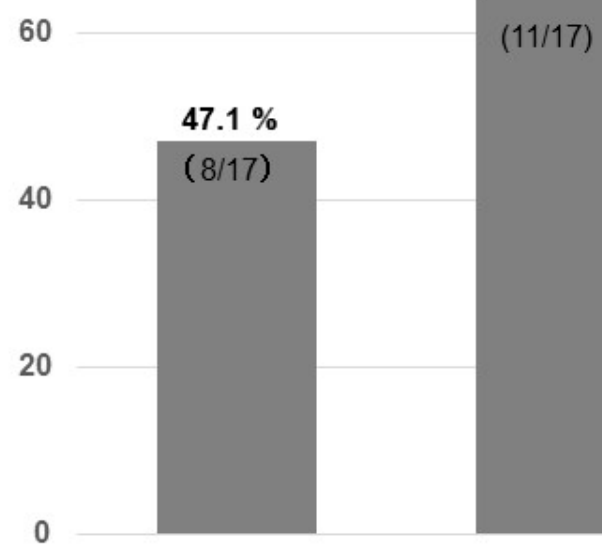

Day 0
$(\%)$

100

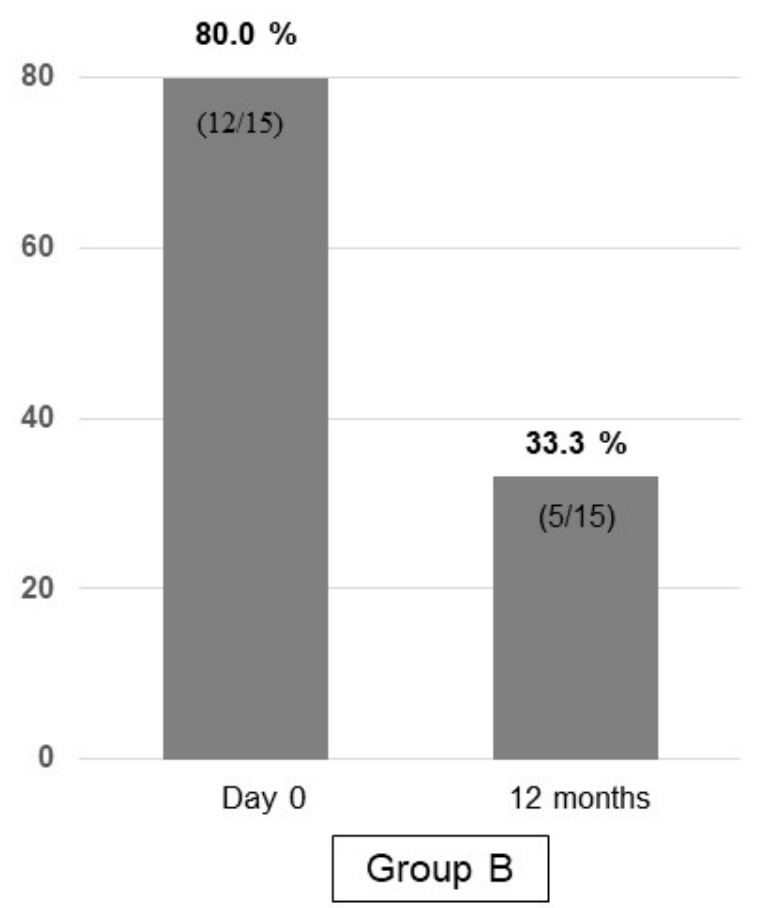

Figure 6. Prevalence of sarcopenia at day 0 and 12 months in the untreated (Group A) and vitamin D-treated (Group B) patients.

Table 2. Comparison between day 0 and 12 months.

\begin{tabular}{cccc}
\hline \multicolumn{4}{c}{ Comparison between day $\mathbf{0}$ and $\mathbf{1 2}$ months in control group (Group A) } \\
\hline Factors & Day 0 & 12 Months & $p$ Value \\
\hline Calcium $(\mathrm{mg} / \mathrm{dL})$ & $8.9(7.9-10.1)$ & $8.9(7.9-10.0)$ & 0.650 \\
Inorganic phosphorus $(\mathrm{mg} / \mathrm{dL})$ & $3.2(2.4-3.6)$ & $3.3(2.0-3.8)$ & 0.500 \\
Serum creatinine $(\mathrm{mg} / \mathrm{dL})$ & $0.67(0.42-2.91)$ & $0.77(0.46-1.86)$ & 0.064 \\
\hline Comparison between day 0 and $\mathbf{1 2}$ months in vitamin D supplementation group (Group B) \\
\hline Factors & Day 0 & $\mathbf{1 2}$ Months & $p$ Value \\
\hline Calcium $(\mathrm{mg} / \mathrm{dL})$ & $8.9(7.9-10.0)$ & $9.0(7.7-10.0)$ & 0.109 \\
Inorganic phosphorus $(\mathrm{mg} / \mathrm{dL})$ & $3.3(2.0-3.8)$ & $3.2(2.9-3.7)$ & 0.317 \\
Serum creatinine $(\mathrm{mg} / \mathrm{dL})$ & $0.75(0.52-1.41)$ & $0.95(0.54-2.63)$ & 0.173 \\
\hline
\end{tabular}

\section{Discussion}

Exercise therapy and BCAA preparations are useful for preventing and treating sarcopenia in patients with chronic liver disease $[4,36,37]$. In the clinical practice guideline recently established by the European Association for the Study of the Liver, the administration of vitamin $\mathrm{D}$ is recommended for patients with cirrhosis accompanied by vitamin $\mathrm{D}$ deficiency [38]. This is the first prospective, randomized, controlled pilot study to demonstrate that vitamin D supplementation significantly increased muscle volume and grip strength in patients with decompensated cirrhosis who had been receiving BCAA preparations.

The annual rates of skeletal muscle volume loss were reported to be $2.2 \%$ for patients with cirrhosis and $1.3 \%, 3.5 \%$ and $6.1 \%$ for those with Child-Pugh class A, B and C, respectively. These data indicate that muscle volume loss is correlated with the extent of hepatic functional reserve impairment [4]. In the present study, a decrease in the SMI after 12 months was observed in 10 (58.8\%) of the 17 untreated patients (Group A) and 
the annual rate of muscle volume loss was 3.3\%, similar to patients with Child-Pugh class B [4]. Contrarily, only 1 (6.7\%) of the 15 patients supplemented with vitamin D (Group B) exhibited a decrease in the SMI after 12 months; the SMI increased at an average of $5.8 \%$ annually in this group. These results suggest that vitamin D supplementation inhibits the decrease in muscle volume or restores lost muscle volume.

The survival rate of patients with cirrhosis accompanied by sarcopenia is lower compared with that of those without sarcopenia, according to a previous report [4]. Therefore, the prevention and treatment of sarcopenia are crucial in improving the survival rate. In Japan, the prevalence of sarcopenia in patients with chronic liver disease ranges from $11 \%$ to $70 \%[4,15,39-42]$. Our previous study also revealed that the prevalence of sarcopenia in patients with cirrhosis was $36.8 \%$ and higher than that in patients without cirrhosis [15].

In the vitamin D-supplemented group (Group B), 7 of the 12 patients who were diagnosed with sarcopenia at day 0 no longer met the diagnostic criteria for sarcopenia after 12 months due to an increase in the SMI. However, we failed to identify the factors associated with increased muscle volume (data not shown). No significant changes in grip strength were observed over time even in Group B, a finding which is consistent with previous reports [33]. However, the grip strength in Group B was significantly increased compared with that in Group A (untreated group). These results suggest that vitamin D supplementation is useful for treating or preventing sarcopenia as it increases the skeletal muscle volume/strength or restores the muscle volume/strength.

Although the mechanism by which vitamin D supplementation increases the skeletal muscle volume remains unclear, some hypotheses have been proposed for the relationship between vitamin D-related factors and sarcopenia. First, vitamin D deficiency induces atrophy of type II fibers (fast muscle fibers) in the skeletal muscle, thus resulting in sarcopenia [43]. Second, the number of VDR in the skeletal muscle decreases with age [23,44], which results in reduced vitamin D activity in the muscle. Vitamin D supplementation may increase or restore the expression of VDR [45]. A randomized controlled trial revealed that vitamin D3 administration for 4 months markedly increased the expression of nuclear VDR in elderly women with low physical performance; a strong correlation between the serum 25(OH)D and VDR expression levels was noted [46]. Third, VDR ablation and vitamin D deficiency may increase the myostatin levels [47]. Myostatin, a cytokine belonging to the transforming growth factor $\beta 1$ family, inhibits the formation of skeletal muscle and, thus, is a negative regulator for muscular hypertrophy [48]. Patients with cirrhosis have higher circulating myostatin levels compared with the control subjects [49].

Adverse reactions to excessive vitamin $\mathrm{D}$ consumption include gastrointestinal disorders (such as anorexia, diarrhea, constipation, nausea and vomiting), sleepiness, headache, muscle pain, thirstiness, weakness and renal calculi, most of which are related to hypercalcemia [50]. Vitamin D toxicity is rare unless the serum 25(OH)D level is $\geq 150 \mathrm{ng} / \mathrm{mL}$ [51]. The present study and other double-blind randomized controlled trials revealed that vitamin D3 supplementation (2000 and 2800 IU per day, respectively) effectively increased the serum 25(OH)D levels even in patients with cirrhosis without inducing adverse effects [52]. Notably, we demonstrated that a relatively low dose (2000 IU per day) is safe and effective for improving vitamin D deficiency and increasing the skeletal muscle volume/strength, even in patients with decompensated cirrhosis. Patient compliance with vitamin D supplementation was found to be excellent. However, the optimal dose for treating patients with cirrhosis accompanied by muscle volume/strength loss remains unclear.

The present study has several limitations. First, this is a pilot study and includes a small number of patients. Second, the study is limited to patients with decompensated cirrhosis receiving BCAA preparations; the effects of vitamin D supplementation alone are unclear. Third, the daily physical activity and exercise in patients before and after treatment intervention were not investigated in detail. Lastly, as described above, the optimal dose of vitamin D supplementation was not examined. Given that sarcopenia in patients with chronic liver disease is associated with low vitamin D levels [15], vitamin D supplementation is rational and may be beneficial for such patients. A large-scale randomized controlled 
study is thus needed to confirm the effects of vitamin D supplementation on the loss of skeletal muscle volume and strength in patients with chronic liver disease, including those with decompensated cirrhosis who are treated with and without BCAA preparations.

In conclusion, the present study suggests that vitamin D supplementation might be an effective and safe treatment option for patients with decompensated cirrhosis to increase or restore the skeletal muscle volume and strength or prevent skeletal muscle volume and strength losses.

Author Contributions: Conceptualization, T.O. and M.A.; methodology, T.O., M.A. and A.T.; formal analysis, T.O. and M.A.; investigation, T.O., H.O., T.K., Y.Y., T.A., K.H., N.I., C.K. and K.K.; drafting or revision of the manuscript, T.O., M.A., A.T. and K.I. All authors have read and agreed to the published version of the manuscript.

Funding: This research received no external funding.

Institutional Review Board Statement: The present study followed the ethical guidelines established in accordance with the 2013 Declaration of Helsinki and was approved by the Institutional Review Board of Nippon Medical School Foundation (approval number: nms-2019-0102-01).

Informed Consent Statement: All patients provided written informed consent.

Data Availability Statement: The data presented in this study are available upon request from the corresponding author. The data are not publicly available due to privacy and ethical reasons.

Acknowledgments: The authors wish to thank all medical doctors from all institutions who were involved in this study.

Conflicts of Interest: The authors declare no conflict of interest.

\section{References}

1. Cruz-Jentoft, A.J.; Landi, F.; Schneider, S.; Zúñiga, C.; Arai, H.; Boirie, Y.; Chen, L.-K.; Fielding, R.A.; Martin, F.C.; Michel, J.-P.; et al. Prevalence of and interventions for sarcopenia in ageing adults: A systematic review. Report of the International Sarcopenia Initiative (EWGSOP and IWGS). Age Ageing 2014, 43, 748-759. [CrossRef] [PubMed]

2. Santilli, V.; Bernetti, A.; Mangone, M.; Paoloni, M. Clinical definition of sarcopenia. Clin. Cases Miner. Bone Metab. 2014, 11, 177-180. [CrossRef]

3. Beaudart, C.; Reginster, J.; Petermans, J.; Gillain, S.; Quabron, A.; Locquet, M.; Slomian, J.; Buckinx, F.; Bruyère, O. Quality of life and physical components linked to sarcopenia: The SarcoPhAge study. Exp. Gerontol. 2015, 69, 103-110. [CrossRef] [PubMed]

4. Hanai, T.; Shiraki, M.; Nishimura, K.; Ohnishi, S.; Imai, K.; Suetsugu, A.; Takai, K.; Shimizu, M.; Moriwaki, H. Sarcopenia im-pairs prognosis of patients with liver cirrhosis. Nutrition 2015, 31, 193-199. [CrossRef]

5. Ninomiya, G.; Fujii, T.; Yamada, S.; Yabusaki, N.; Suzuki, K.; Iwata, N.; Kanda, M.; Hayashi, M.; Tanaka, C.; Nakayama, G.; et al. Clinical impact of sarcopenia on prognosis in pancreatic ductal adenocarcinoma: A retrospective cohort study. Int. J. Surg. 2017, 39, 45-51. [CrossRef]

6. Costa, T.M.D.R.L.; Costa, F.M.; Moreira, C.A.; Rabelo, L.M.; Boguszewski, C.L.; Borba, V.Z.C. Sarcopenia in COPD: Relationship with COPD severity and prognosis. J. Bras. Pneumol. 2015, 41, 415-421. [CrossRef]

7. Benadon, B.; Servagi-Vernat, S.; Quero, L.; Cattan, P.; Guillerm, S.; Hennequin, V.; Aparicio, T.; Lourenço, N.; Bouché, O.; Hennequin, C. Sarcopenia: An important prognostic factor for males treated for a locally advanced esophageal carcinoma. Dig. Liver Dis. 2020, 52, 1047-1052. [CrossRef] [PubMed]

8. Toshikuni, N.; Arisawa, T.; Tsutsumi, M. Nutrition and exercise in the management of liver cirrhosis. World J. Gastroenterol. 2014, 20, 7286-7297. [CrossRef]

9. Nishikawa, H.; Shiraki, M.; Hiramatsu, A.; Moriya, K.; Hino, K.; Nishiguchi, S. Japan Society of Hepatology guidelines for sarcopenia in liver disease (1st edition): Recommendation from the working group for creation of sarcopenia assessment criteria. Hepatol. Res. 2016, 46, 951-963. [CrossRef]

10. Hiraoka, A.; Michitaka, K.; Kiguchi, D.; Izumoto, H.; Ueki, H.; Kaneto, M.; Kitahata, S.; Aibiki, T.; Okudaira, T.; Tomida, H.; et al. Efficacy of branched-chain amino acid supplementation and walking exercise for preventing sarcopenia in patients with liver cirrhosis. Eur. J. Gastroenterol. Hepatol. 2017, 29, 1416-1423. [CrossRef] [PubMed]

11. Borack, M.S.; Volpi, E. Efficacy and Safety of Leucine Supplementation in the Elderly. J. Nutr. 2016, 146, 2625S-2629S. [CrossRef]

12. Kitajima, Y.; Takahashi, H.; Akiyama, T.; Murayama, K.; Iwane, S.; Kuwashiro, T.; Tanaka, K.; Kawazoe, S.; Ono, N.; Eguchi, T.; et al. Supplementation with branched-chain amino acids ameliorates hypoalbuminemia, prevents sarcopenia, and reduces fat accumulation in the skeletal muscles of patients with liver cirrhosis. J. Gastroenterol. 2017, 53, 427-437. [CrossRef] 
13. Garcia-Pagan, J.C.; Santos, C.; Barberá, J.A.; Luca, A.; Roca, J.; Rodriguez-Roisin, R.; Bosch, J.A.; Rodes, J.O. Physical exercise increases portal pres-sure in patients with cirrhosis and portal hypertension. Gastroenterology 1996, 111, $1300-1306$. [CrossRef] [PubMed]

14. Dietrich, R.; Bachmann, C.; Lauterburg, B.H. Exercise-Induced Hyperammonemia in Patients with Compensated Chronic Liver Disease. Scand. J. Gastroenterol. 1990, 25, 329-334. [CrossRef]

15. Okubo, T.; Atsukawa, M.; Tsubota, A.; Yoshida, Y.; Arai, T.; Iwashita, A.; Itokawa, N.; Kondo, C.; Iwakiri, K. Relationship between serum vitamin D level and sarcopenia in chronic liver disease. Hepatol. Res. 2020, 50, 588-597. [CrossRef] [PubMed]

16. Dattola, A.; Silvestri, M.; Bennardo, L.; Passante, M.; Scali, E.; Patruno, C.; Nisticò, S.P. Role of Vitamins in Skin Health: A Systematic Review. Curr. Nutr. Rep. 2020, 9, 226-235. [CrossRef] [PubMed]

17. DeLuca, H.F. Overview of general physiologic features and functions of vitamin D. Am. J. Clin. Nutr. 2004, 80, 1689S-1696S. [CrossRef]

18. Atsukawa, M.; Tsubota, A.; Shimada, N.; Yoshizawa, K.; Abe, H.; Asano, T.; Ohkubo, Y.; Araki, M.; Ikegami, T.; Kondo, C.; et al. Influencing factors on serum 25-hydroxyvitamin D3 levels in Japanese chronic hepatitis C patients. BMC Infect. Dis. 2015, 15, 344. [CrossRef] [PubMed]

19. Arai, T.; Atsukawa, M.; Tsubota, A.; Koeda, M.; Yoshida, Y.; Okubo, T.; Nakagawa, A.; Itokawa, N.; Kondo, C.; Nakatsuka, K.; et al. Association of vitamin D levels and vitamin D-related gene polymorphisms with liver fibrosis in patients with biopsy-proven nonalcoholic fatty liver disease. Dig. Liver Dis. 2019, 51, 1036-1042. [CrossRef]

20. Atsukawa, M.; Tsubota, A.; Shimada, N.; Yoshizawa, K.; Abe, H.; Asano, T.; Ohkubo, Y.; Araki, M.; Ikegami, T.; Okubo, T.; et al. Effect of native vitamin D3supplementation on refractory chronic hepatitis $\mathrm{C}$ patients in simeprevir with pegylated interferon/ribavirin. Hepatol. Res. 2015, 46, 450-458. [CrossRef] [PubMed]

21. Arai, T.; Atsukawa, M.; Tsubota, A.; Kawano, T.; Koeda, M.; Yoshida, Y.; Tanabe, T.; Okubo, T.; Hayama, K.; Iwashita, A.; et al. Factors influencing subclinical atherosclerosis in patients with biopsy-proven nonalcoholic fatty liver disease. PLoS ONE 2019, 14, e0224184. [CrossRef]

22. Saeki, C.; Kanai, T.; Nakano, M.; Oikawa, T.; Torisu, Y.; Saruta, M.; Tsubota, A. Low Serum 25-Hydroxyvitamin D Levels Are Related to Frailty and Sarcopenia in Patients with Chronic Liver Disease. Nutrients 2020, 12, 3810. [CrossRef]

23. Bischoff-Ferrari, H.A.; Borchers, M.; Gudat, F.; Dürmüller, U.; Stähelin, H.B.; Dick, W. Vitamin D Receptor Expression in Human Muscle Tissue Decreases With Age. J. Bone Miner. Res. 2004, 19, 265-269. [CrossRef] [PubMed]

24. Simpson, R.U.; Thomas, G.A.; Arnold, A.J. Identification of 1,25-dihydroxyvitamin D3 receptors and activities in muscle. J. Biol. Chem. 1985, 25, 8882-8891. [CrossRef]

25. Tanaka, M.; Kishimoto, K.N.; Okuno, H.; Saito, H.; Itoi, E. Vitamin D receptor gene silencing effects on differentiation of myogenic cell lines. Muscle Nerve 2014, 49, 700-708. [CrossRef] [PubMed]

26. Visser, M.; Deeg, D.J.H.; Lips, P. Low Vitamin D and High Parathyroid Hormone Levels as Determinants of Loss of Muscle Strength and Muscle Mass (Sarcopenia): The Longitudinal Aging Study Amsterdam. J. Clin. Endocrinol. Metab. 2003, 88, 5766-5772. [CrossRef] [PubMed]

27. Wicherts, I.S.; Van Schoor, N.M.; Boeke, A.J.P.; Visser, M.; Deeg, D.J.H.; Smit, J.; Knol, D.L.; Lips, P. Vitamin D Status Predicts Physical Performance and Its Decline in Older Persons. J. Clin. Endocrinol. Metab. 2007, 92, 2058-2065. [CrossRef]

28. Suzuki, T.; Kwon, J.; Kim, H.; Shimada, H.; Yoshida, Y.; Iwasa, H.; Yoshida, H. Low Serum 25-Hydroxyvitamin D Levels Associated With Falls Among Japanese Community-Dwelling Elderly. J. Bone Miner. Res. 2008, 23, 1309-1317. [CrossRef]

29. Remelli, F.; Vitali, A.; Zurlo, A.; Volpato, S. Vitamin D Deficiency and Sarcopenia in Older Persons. Nutrients 2019, 11, 2861. [CrossRef]

30. Granic, A.; Hill, T.R.; Davies, K.; Jagger, C.; Adamson, A.; Siervo, M.; Kirkwood, T.B.L.; Mathers, J.C.; Sayer, A.A. Vitamin D Status, Muscle Strength and Physical Performance Decline in Very Old Adults: A Prospective Study. Nutrients 2017, 9, 379. [CrossRef]

31. Hirani, V.; Cumming, R.; Naganathan, V.; Blyth, F.; Le Couteur, D.G.; Hsu, B.; Handelsman, D.J.; Waite, L.M.; Seibel, M.J. Longitudinal Associations Between Vitamin D Metabolites and Sarcopenia in Older Australian men: The Concord Health and Aging in Men Project. J. Gerontol. Ser. A Biol. Sci. Med. Sci. 2018, 73, 131-138. [CrossRef] [PubMed]

32. Bischoff, H.A.; Stähelin, H.B.; Dick, W.; Akos, R.; Knecht, M.; Salis, C.; Nebiker, M.; Theiler, R.; Pfeifer, M.; Begerow, B.; et al. Effects of Vitamin D and Calcium Supplementation on Falls: A Randomized Controlled Trial. J. Bone Miner. Res. 2003, 18, 343-351. [CrossRef]

33. El Hajj, C.; Fares, S.; Chardigny, J.M.; Boirie, Y.; Walrand, S. Vitamin D supplementation and muscle strength in pre-sarcopenic elderly Lebanese people: A randomized controlled trial. Arch. Osteoporos. 2019, 14, 4. [CrossRef]

34. Stokes, C.S.; Volmer, D.A.; Grünhage, F.; Lammert, F. Vitamin D in chronic liver disease. Liver Int. 2013, 33, 338-352. [CrossRef]

35. Michael, F. Vitamin D deficiency. N. Engl. J. Med. 2007, 357, 266-281.

36. Hayashi, F.; Matsumoto, Y.; Momoki, C.; Yuikawa, M.; Okada, G.; Hamakawa, E.; Kawamura, E.; Hagihara, A.; Toyama, M.; Fujii, H.; et al. Physical inactivity and insufficient dietary intake are associated with the frequency of sarcopenia in patients with compensated viral liver cirrhosis. Hepatol. Res. 2013, 43, 1264-1275. [CrossRef]

37. Iwasa, M.; Sugimoto, R.; Takei, Y. Patients with hyponatremic cirrhosis have low-grade cerebral edema and poor quality-of-life. Ann. Hepatol. 2014, 13, 407-408. [CrossRef]

38. European Association for the Study of the Liver. EASL Clinical Practice Guidelines on nutrition in chronic liver disease. J. Hepatol. 2019, 70, 172-193. [CrossRef] [PubMed] 
39. Iritani, S.; Imai, K.; Takai, K.; Hanai, T.; Ideta, T.; Miyazaki, T.; Suetsugu, A.; Shiraki, M.; Shimizu, M.; Moriwaki, H. Skeletal muscle depletion is an independent prognostic factor for hepatocellular carcinoma. J. Gastroenterol. 2015, 50, 323-332. [CrossRef] [PubMed]

40. Hanai, T.; Shiraki, M.; Watanabe, S.; Kochi, T.; Imai, K.; Suetsugu, A.; Takai, K.; Moriwaki, H.; Shimizu, M. Sarcopenia predicts minimal hepatic encephalopathy in patients with liver cirrhosis. Hepatol. Res. 2017, 47, 1359-1367. [CrossRef]

41. Hayashi, M.; Abe, K.; Fujita, M.; Okai, K.; Takahashi, A.; Ohira, H. Association between sarcopenia and osteoporosis in chronic liver disease. Hepatol. Res. 2018, 48, 893-904. [CrossRef]

42. Saeki, C.; Takano, K.; Oikawa, T.; Aoki, Y.; Kanai, T.; Takakura, K.; Nakano, M.; Torisu, Y.; Sasaki, N.; Abo, M.; et al. Comparative assessment of sarcopenia using the JSH, AWGS, and EWGSOP2 criteria and the relationship between sarcopenia, osteoporosis, and osteosarcopenia in patients with liver cirrhosis. BMC Musculoskelet. Disord. 2019, 20, 1-12. [CrossRef] [PubMed]

43. Ceglia, L.; Morais, M.D.S.; Park, L.K.; Morris, E.; Harris, S.S.; Bischoff-Ferrari, H.A.; Fielding, R.A.; Dawson-Hughes, B. Multi-step immunofluorescent analysis of vitamin D receptor loci and myosin heavy chain isoforms in human skeletal muscle. J. Mol. Histol. 2010, 41, 137-142. [CrossRef]

44. Ceglia, L.; Harris, S.S. Vitamin D and Its Role in Skeletal Muscle. Calcif. Tissue Int. 2013, 92, 151-162. [CrossRef] [PubMed]

45. Pojednic, R.M.; Ceglia, L.; Olsson, K.; Gustafsson, T.; Lichtenstein, A.H.; Dawson-Hughes, B.; Fielding, R.A. Effects of 1,25dihydroxyvitamin D3 and vitamin D3 on the expression of the vitamin d receptor in human skeletal muscle cells. Calcif. Tissue Int. 2014, 96, 256-263. [CrossRef]

46. Ceglia, L.; Niramitmahapanya, S.; Morais, M.D.S.; Rivas, D.; Harris, S.S.; Bischoff-Ferrari, H.; Fielding, R.A.; Dawson-Hughes, B. A Randomized Study on the Effect of Vitamin D3Supplementation on Skeletal Muscle Morphology and Vitamin D Receptor Concentration in Older Women. J. Clin. Endocrinol. Metab. 2013, 98, E1927-E1935. [CrossRef] [PubMed]

47. Girgis, C.M.; Cha, K.M.; Houweling, P.J.; Rao, R.; Mokbel, N.; Lin, M.; Clifton-Bligh, R.J.; Gunton, J.E. Vitamin D Receptor Ablation and Vitamin D Deficiency Result in Reduced Grip Strength, Altered Muscle Fibers, and Increased Myostatin in Mice. Calcif. Tissue Int. 2015, 97, 602-610. [CrossRef] [PubMed]

48. McPherron, A.C.; Lawler, A.M.; Lee, S.J. Regulation of skeletal muscle mass in mice by a new TGF-beta superfamily member. Nature 1997, 387, 83-90. [CrossRef] [PubMed]

49. Nishikawa, H.; Enomoto, H.; Ishii, A.; Iwata, Y.; Miyamoto, Y.; Ishii, N.; Yuri, Y.; Hasegawa, K.; Nakano, C.; Nishimura, T.; et al. Elevated serum myostatin level is associated with worse survival in patients with liver cirrhosis. J. Cachex Sarcopenia Muscle 2017, 8, 915-925. [CrossRef]

50. Schwalfenberg, G. Not enough vitamin D: Health consequences for Canadians. Can. Fam. Physician 2007, 53, 841-854.

51. Holick, M.; Binkley, N.C.; Bischoff-Ferrari, H.A.; Gordon, C.M.; Hanley, D.A.; Heaney, R.P.; Murad, M.H.; Weaver, C.M. Evaluation, Treatment, and Prevention of Vitamin D Deficiency: An Endocrine Society Clinical Practice Guideline. J. Clin. Endocrinol. Metab. 2011, 96, 1911-1930. [CrossRef] [PubMed]

52. Pilz, S.; Putz-Bankuti, C.; Gaksch, M.; Spindelboeck, W.; Haselberger, M.; Rainer, F.; Pösch, A.; Kreuzer, P.; Stojakovic, T.; Stadlbauer, V.; et al. Effects of Vitamin D Supplementation on Serum 25-Hydroxyvitamin D Concentrations in Cirrhotic Patients: A Randomized Controlled Trial. Nutrients 2016, 8, 278. [CrossRef] [PubMed] 